\title{
PERAN PERKEMBANGAN TEKNOLOGI INFORMASI DAN KOMUNIKASI DALAM PEMBELAJARAN ILEARNING PLUS DI UNIVERSITAS RAHARJA
}

\author{
I. Handayani'), E. Febriyanto ${ }^{2)}$, C. Y. Kristanti ${ }^{3)}$ \\ Jurusan Sistem Informasi, Universitas Raharja, Tangerang \\ Email: 1indri@raharja.info, ²erick@raharja.info, ${ }^{3}$ citra.yulian@raharja.info
}

\begin{abstract}
ABSTRAK
Saat ini Indonesia telah memasuki era Industri 4.0 dimana perkembangan Teknologi Informasi dan Komunikasi (TIK) sangat pesat. Berbagai manfaat pun bermunculan khususnya dalam bidang Pendidikan. Teknologi Informasi dan Komunikasi memegang peran sangat penting dalam kecanggihan berkomunikasi. iLearning Plus merupakan inovasi metode pembelajaran Universitas Raharja secara jarak jauh dimana para mahasiswa tidak perlu datang ke kampus untuk melakukan kegiatan pembelajaran. Disinilah peran Teknologi Informasi dan Komunikasi sangat diperlukan guna kelancaran kegiatan pembelajaran. Teknologi Informasi dan Komunikasi digunakan sebagai media pembelajaran sekaligus media komunikasi antara mahasiswa dengan dosen. Sebagai media pembelajaran Mahasiswa akan mendapatkan materi perkuliahan beserta latihannya melalui website tanpa perlu tatap muka dengan Dosen yang bersangkutan. Materi yang diberikan dapat berupa teks ataupun video. Meskipun tidak bertatap muka, komunikasi antar Mahasiswa dan Dosen tidak lepas begitu saja, Teknologi Informasi dan Komunikasi sebagai media komunikasi menyediakan sarana bagi Mahasiswa dan Dosen sehingga antar Mahasiswa dan Dosen masih dapat berkomunikasi untuk membahas materi perkuliahan yang masih belum dapat dimengerti oleh Mahasiswa. Penelitian ini merupakan penelitian yang bersifat deskriptif dengan maksud dan tujuan untuk mendeskripsikan tentang peran perkembangan Teknologi Informasi dan Komunikasi pada metode pembelajaran iLearning Plus.
\end{abstract}

Kata kunci: Perkembangan TIK, iLearning Plus, Universitas Raharja

\begin{abstract}
At present Indonesia has entered the era of Industry 4.0 where the development of Information and Communication Technology (ICT) is very rapid. Various benefits also emerged, especially in the field of Education. Information and Communication Technology plays a very important role in the sophistication of communication. iLearning Plus is a learning method innovation at Raharja University remotely where students do not need to come to campus to conduct learning activities. This is where the role of Information and Communication Technology is very necessary for the smooth learning activities. Information and Communication Technology is used as a learning media as well as a medium of communication between students and lecturers. As a learning media Students will get lecture material and training through a website without the need to face to face with the lecturer in question. The material provided may be either text or video. Although not face-to-face, communication between students and lecturers did not go away, Information and Communication Technology as a communication media provided a means for students and lecturers so that students and lecturers could still communicate to discuss lecture material that students still could not understand. This research is a descriptive study with the intent and purpose of describing the role of the development of Information and Communication Technology in the iLearning Plus learning method.
\end{abstract}

Keywords : ICT Development, iLearning Plus, Raharja University 


\section{PENDAHULUAN}

Tidak dapat dipungkiri perkembangan Teknologi Informasi dan Komunikasi (TIK) saat ini sangat pesat. Teknologi Informasi dan Komunikasi memegang berbagai peran penting di kehidupan salah satunya yaitu dalam dunia pendidikan. Dunia pendidikan memerlukan Teknologi Informasi dan Komunikasi sebagai alat penyampaian informasi sehingga informasi dapat diakses kapanpun dan dimanapun.

Universitas Raharja merupakan salah satu institusi pendidikan yang menggunakan Teknologi Informasi dan Komunikasi dalam kegiatan perkuliahannya sebagai media penyampaian informasi yang berkaitan dengan berbagai aspek kegiatan yang ada dalam Universitas Raharja.

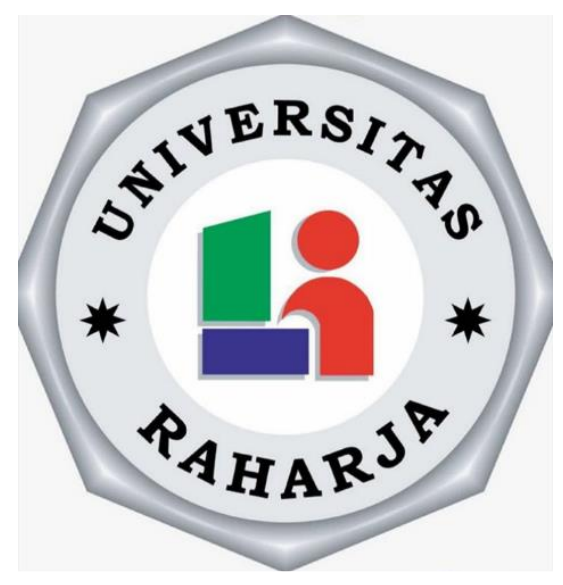

Gambar 1. Logo Universitas Raharia

Gambar 1 merupakan logo dari Universitas Raharja, yang merupakan salah satu Universitas yang bergerak dalam bidang Teknologi Informasi dan Komunikasi. Universitas Raharja memiliki hubungan erat kaitannya dengan peran perkembangan Teknologi Informasi dan Komunikasi, dimana Teknologi Informasi dan Komunikasi diperlukan sebagai media penyampaian informasi, media pembelajaran sekaligus media berkomunikasi dalam kegiatan belajar mengajar terutama untuk metode pembelajaran iLearning Plus.

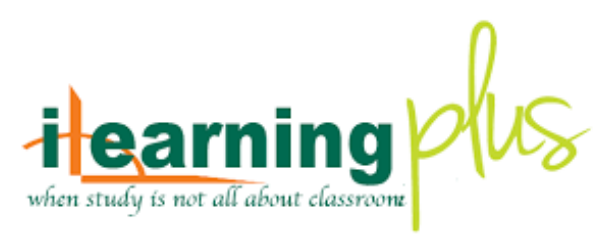

Gambar 2. Logo iLearning Plus

Gambar 2 merupakan logo dari iLearning Plus. iLearning Plus adalah perkuliahan jarak jauh secara online. iLearning Plus merupakan sistem pembelajaran fleksibilitas yang dapat menghemat waktu, biaya dan tenaga. iLearning sangat berbeda dengan pembelajaran konvensional, jika perkuliahan konvensional harus datang ke kampus untuk mengikuti perkuliahan, maka iLearning hanya perlu memiliki pc ataupun laptop yang terhubung ke internet maka bisa langsung mengikuti perkuliahan sehingga kegiatan perkuliahan dapat dilakukan dengan mudah kapan saja dan dimana saja.

iLearning Plus mengandalkan perkembangan Teknologi Informasi dan Komunikasi sebagai metode dalam pembelajarannya. Metode pembelajaran yang efektif adalah metode yang digunakan oleh dosen yang bukan saja terfokus kepada hasil yang dicapai oleh mahasiswa, namun bagaimana proses pembelajaran yang efektif dapat memberikan pemahaman yang baik yang dapat dimengerti oleh mahasiswa. Metode yang digunakan iLearning Plus yaitu Metode Learning Management System (LMS).

Learning Management System (LMS) adalah suatu pengelolaan pembelajaran yang mempunyai fungsi untuk memberikan sebuah materi, mendukung kolaborasi, menilai kinerja siswa, dan menghasilkan laporan yang berguna untuk memaksimalkan efektivitas dari sebuah pembelajaran[1]. Dengan adanya Learning Management System (LMS) maka terdapat interaksi komunikasi antara dosen dengan mahasiswa ataupun mahasiswa dengan mahasiswa lainnya. 
Learning Management System (LMS) berperan sebagai media pembelajaran, dimana dosen akan menyimpan bahan materi perkuliahan melalui Learning Management System (LMS) tersebut. Selain itu dosen juga dapat memberikan tugas berupa assignment kepada mahasiswa serta batas waktu untuk pengumpulan tugas tersebut.

Komunikasi juga sangat diperlukan dalam kegiatan pembelajaran secara online. Disinilah peran Learning Management System (LMS) sebagai media komunikasi dibutuhkan. Mahasiswa dapat berinteraksi dengan dosen maupun mahasiswa lainnya guna menunjang kelancaran proses kegiatan belajar mengajar pada iLearning Plus di Universitas Raharja.

Penelitian ini memiliki tujuan untuk mendeskripsikan peran perkembangan Teknologi Informasi dan Komunikasi pada metode pembelajaran iLearning Plus yang ada di Universitas Raharja. Penelitian ini nantinya akan memaparkan peranan Teknologi Informasi dan Komunikasi terkait pembelajaran jarak jauh. Dengan data-data yang sudah diperoleh, akan dilakukan analisis deskriptif mengenai keadaan saat ini terutama tentang perkembangan Teknologi Informasi dan Komunikasi pada iLearning Plus di Universitas Raharja.

\section{METODE PENELITIAN}

Dalam penelitian kali ini menerapkan beberapa metode penelitian yaitu Metode Deskriptif dan Metode Studi Pustaka.

\section{A. Metode Deskriptif}

Metode deskriptif merupakan metode penelitian yang bertujuan untuk mengumpulkan informasi aktual secara rinci mengenai suatu gejala yang ada sesuai dengan yang diteliti. Oleh karena itu, dalam metode ini, peneliti tidak menekankan untuk mengisi hipotesa atau menguji variabel untuk mengetahui kebenaran teori melainkan hanya mendeskripsikan informasi apa adanya sesuai keadaan yang diteliti[2]. Dengan menggunakan metode ini, peneliti berusaha untuk mengumpulkan informasi atau data mengenai perkembangan teknologi informasi dan komunikasi dalam pembelajaran iLearning Plus di Universitas Raharja guna mendeskripsikan metode pembelajaran yang digunakan.

\section{B. Metode Studi Pustaka}

Studi Pustaka merupakan metode pengumpulan data dengan mencari informasi yang relevan sesuai dengan topik permasalahan yang menjadi objek penelitian. Peran perkembangan TIK dalam pembelajaran iLearning Plus, terdapat beberapa literature review yang telah ditinjau untuk menghindari pengulangan dan sekaligus untuk meneruskan penelitian yang sudah ada sebelumnya. Beberapa literature review diantaranya sebagai berikut :

a. Penelitian yang telah dilakukan oleh Untung Rahardja, Qurotul Aini dan Siti Ria Zuliana dari Perguruan Tinggi Raharja pada tahun 2016 yang berjudul "METODE LEARNING MANAGEMENT SYSTEM (LMS) IDU UNTUK MENDUKUNG KEGIATAN BELAJAR MENGAJAR MIT PADA PERGURUAN TINGGI RAHARJA". Dalam penelitiannya mereka membahas tentang penerapan Metode Learning Management System (LMS) menggunakan iDu pada kegiatan belajar mengajar di Perguruan Tinggi Raharja pada kelas Mastering Information Technology (MIT) yang bertujuan untuk mengetahui mengukur keberhasilan proses pembelajaran.

b. Penelitian yang dilakukan oleh Qurotul Aini, Hani Dewi Ariesanti, Kitab Suci dari STMIK Raharja pada Technomedia Journal (TMJ) Vol.1 No.2 Edisi Februari 2017 yang berjudul "Penerapan iDu iLearning Plus Berbasis Gamification Sebagai Media Pembelajaran Jarak Jauh Pada Perguruan Tinggi". Dalam penelitian yang telah mereka lakukan ini membahas tentang penerapan gamifikasi didalam pembelajaran online agar proses belajar mengajar pada iLearning Plus menjadi lebih efektif dan juga terdapatnya leaderboard yang berupa level keaktifan mahasiswa, guna memantau seberapa aktif mahasiswa dalam mengerjakan tugas maupun mempelajari materi perkuliahan yang sudah terdapat di iDu.

c. Penelitian yang telah dilakukan oleh Muhamad Yusup, Qurotul Aini dan Komala Dwi Pertiwi dari STMIK Raharja pada Technomedia Journal (TMJ) Vol.1 No.1 Edisi Agustus 2016 yang berjudul "Media Audio Visual Menggunakan Videoscribe Sebagai Penyajian Informasi Pembelajaran Pada Kelas Sistem Operasi". Dalam penelitiannya mereka membahas tentang pengimplementasian video pembelajaran pada kelas sistem operasi program iLearning Plus menggunakan Videoscribe. Videoscribe adalah aplikasi online dan bernuansa multimedia serta dapat berupa foto, gambar, teks, musik, dan background yang dapat dipilih sesuai keinginan. Penelitian ini bertujuan agar setelah adanya video pembelajaran berupa media audio visual sebagai penyajian informasi pembelajaran, mahasiswa dapat dengan mudah memahami dan mendalami materi yang telah disampaikan. 
d. Penelitian yang telah dilakukan oleh Qurotul Aini, Rubin Hakita Irwin dan Eka Marjayanti dari STMIK Raharja pada Technomedia Journal (TMJ) Vol.1 No.2 Edisi Februari 2017 yang berjudul "Notifikasi Pembelajaran iLearning Melalui Media Aplikasi iDu dengan Menggunakan E-mail Rinfo". Dalam penelitian yang dilakukan ini membahas tentang penyampaian informasi secara online pada media aplikasi iDu melalui E-mail Rinfo sehingga penyampaian informasi dapat dilakukan di mana saja dan kapan saja tanpa harus datang ke kampus, selain itu informasi yang disampaikan dapat lebih menyeluruh dan tepat kepada mahasiswa tidak terbatas oleh ruang dan waktu.

e. Penelitian yang dilakukan oleh Untung Rahardja, Qurotul Aini, Desy Apriani dan Alfiah Khoirunisa dari STMIK Raharja, Tangerang pada Technomedia Journal (TMJ) Vol.3 No.2 Edisi Februari 2019 yang berjudul "Optimalisasi Informasi Manajemen Laporan Assignment Pada Website Berbasis Content Management System". Dalam penelitiannya mereka membahas tentang memaksimalkan cara menata laporan assignment mahasiswa dalam sebuah website content management system guna efisiensi manajemen waktu yang dapat diterapkan sebagai manajemen pendidikan di pendidikan tinggi. Diharapkan dengan adanya metode ini dapat meningkatkan manajemen waktu dalam belajar sehingga memotivasi mahasiswa untuk mengeksplorasi kemampuan dalam proses pembelajaran yang ada.

f. Penelitian yang telah dilakukan oleh Abdul Hayat, Siti Maesaroh dan Mira Ardiana dari STMIK Raharja, Tangerang pada Technomedia Journal (TMJ) Vol.3 No.2 Edisi Februari 2019 yang berjudul "Perancangan Aplikasi Green Media Berbasis Smartphone Sebagai Sarana Media Education dan Entertainment Pada Perguruan Tinggi ". Dalam penelitiannya kali ini membahas tentang aplikasi Green Media yaitu aplikasi yang berisi konten media entertainment dan education. Mahasiswa dapat mengakses aplikasi Green Media untuk mendengarkan siaran radio, menyaksikan film karya-karya mahasiswa, dan berita terbaru seputar Perguruan Tinggi. Dengan adanya aplikasi Green Media diharapkan, mahasiswa pada Perguruan Tinggi dapat mengetahui seputar prestasi dan kreatifitas terbaru apa saja yang sedang diraih oleh Perguruan Tinggi saat ini.

g. Penelitian yang dilakukan oleh Untung Rahardja, Nikita Jova Tejosuwito dan Fernanda Setyobudi Armansyah dari STMIK Raharja pada Technomedia Journal (TMJ) Vol.1 No.2 Edisi Februari 2017 yang berjudul "Perancangan Aplikasi PEN+ Berbasis Mobile Untuk Memudahkan Kinerja Dosen Pada Perguruan Tinggi". Dalam penelitian yang telah dilakukan ini mereka membahas tentang aplikasi Pen+ berbasis mobile yang dapat di akses secara online untuk dosen agar dapat melakukan penginputan nilai dengan lebih cepat dan efektif. Aplikasi Pen+ berbasis mobile yang digunakan juga diharapkan mempermudah pelayanan penilaian secara online.

h. Penelitian yang telah dilakukan oleh Sarah Bibi dari IKIP PGRI Pontianak pada Jurnal Pendidikan Informatika dan Sains, Vol.4, No. 2, Desember 2015 yang berjudul "EFEKTIVITAS PENERAPAN BLENDED LEARNING TERHADAP TINGKAT PEMAHAMAN MAHASISWA MATA KULIAH ALGORITMA DAN PEMROGRAMAN". Dalam penelitian yang dilakukan ini membahas tentang perbedaan pemahaman mahasiswa antara pembelajaran model blended learning dengan pembelajaran konvensional dan bertujuan untuk mengetahui peningkatan pemahaman mahasiswa akibat penerapan pembelajaran model blended learning. Penelitian ini menghasilkan data berupa adanya peningkatan pemahaman mahasiswa akibat penerapan pembelajaran model blended learning rata-rata peningkatan 37,59 .

i. Penelitian yang dilakukan oleh Emria Fitri, Neviyarni dan Ifdil dari Universitas Negeri Padang pada Jurnal Psikologi Pendidikan \& Konseling Volume 2 Nomor 2 Juni 2016 yang berjudul "Efektivitas layanan informasi dengan menggunakan metode blended learning untuk meningkatkan motivasi belajar". Dalam penelitiannya mereka membahas tentang layanan informasi dengan menggunakan metode blended learning terbukti efektif dalam meningkatkan motivasi belajar siswa. Hal tersebut dibuktikan dengan adanya temuan penelitian yang mengungkapkan bahwa tingkat motivasi belajar siswa kelompok pada pretest dan posttest mengalami peningkatan, terdapat perbedaan yang signifikan dari motivasi belajar siswa kelompok sebelum dan sesudah diberikan perlakuan layanan informasi menggunakan metode blended learning.

j. Penelitian yang telah dilakukan oleh Imani Mwalumbwe dan Joel S. Mtebe pada The Electronic Journal of Information Systems in Developing Countries tahun 2017. Dalam penelitiannya kali ini membahas tentang perancangan dan pengembangan alat Learning Analytics dan menggunakan alat untuk menentukan penyebab antara penggunaan LMS dan kinerja siswa. Dalam penelitian ini menemukan bahwa Postingan Forum, Interaksi Teman, dan Latihan memiliki dampak pada 
kinerja belajar siswa. Namun, penelitian ini tidak menemukan bahwa jumlah unduhan, frekuensi masuk, waktu yang dihabiskan di LMS memiliki dampak pada kinerja siswa.

k. Penelitian yang dilakukan oleh Mufidatul Islamiyah dan Lilis Widayanti dari STMIK Asia Malang pada Jurnal IImiah Teknologi dan Informasi ASIA (JITIKA) Vol.10, No.1, Februari 2016 yang berjudul "Efektifitas Pemanfaatan E-Learning Berbasis Website Terhadap Hasil Belajar Mahasiswa STMIK Asia Malang Pada Mata Kuliah Fisika Dasar". Dalam penelitian yang telah dilakukan ini mereka membahas tentang Pemanfaatan teknologi informasi dalam pembelajaran E-Learning yang berada pada sekolah tinggi manajemen dan ilmu Komputer (STMIK) yang bertujuan untuk meningkatkan kualitas pembelajaran mahasiswa dalam pemahaman materi pembelajaran.

I. Penelitian yang dilakukan oleh Roni Yunis dan Kristian Telaumbanua pada Jurnal Nasional Teknik Elektro dan Teknologi Informasi (JNTETI) Vol. 6, No. 1, Februari 2017 yang berjudul "Pengembangan E-Learning Berbasiskan LMS untuk Sekolah, Studi Kasus SMA/SMK di Sumatera Utara". Dalam penelitiannya kali ini mereka membahas tentang pengembangan elearning yang disesuaikan dengan kebutuhan sekolah di tingkat SMA/SMK dengan studi kasus sekolah yang ada di Sumatera Utara. E-learning dikembangkan dengan menggunakan Learning Management System (LMS) eFront berbasis open source yang akan dikembangkan dan dimodifikasi sesuai dengan kebutuhan pengguna.

m. Penelitian yang dilakukan oleh Komang Sabda Kusumantara, Gede Saindra Santyadiputra, dan Nyoman Sugihartini dari Universitas Pendidikan Ganesha pada Jurnal Pendidikan Teknologi dan Kejuruan Vol. 14, No. 2, Juli 2017 yang berjudul "PENGARUH E-LEARNING SCHOOLOGY TERHADAP HASIL BELAJAR SIMULASI DIGITAL DENGAN MODEL PEMBELAJARAN SAVI". Dalam penelitian yang mereka lakukan kali ini mereka membahas tentang pengaruh media pembelajaran E-learning Schoology terhadap hasil belajar siswa kelas X Administrasi Perkantoran SMK Negeri 1 Singaraja, hasil yang didapatkan adalah kelompok yang menggunakan media pembelajaran E-learning Schoology lebih tinggi dibandingkan dengan kelompok yang menggunakan media pembelajaran konvensional sehingga dapat disimpulkan bahwa media pembelajaran E-learning Schoology lebih baik dengan rata-rata hasil belajar yang lebih tinggi.

Dari beberapa Studi Pustaka yang sudah ditelaah di atas, dapat disimpulkan bahwa sudah banyak penelitian yang dilakukan mengenai pemanfaatan teknologi di bidang pendidikan sebagai metode pembelajaran secara online dimana nantinya dapat digunakan sebagai metode pembelajaran jarak jauh

\section{HASIL DAN PEMBAHASAN}

Dengan perkembangan teknologi saat ini, tidak ada sedikit pun celah bagi para sumber daya untuk tidak memanfaatkan teknologi tersebut, terlebih dalam bidang pendidikan. Pemanfaatan media komunikasi dan informasi dalam pembelajaran menjadi sebuah kebutuhan ditengah perkembangan zaman yang serba cepat ini. Dunia pendidikan diharapkan tidak tertinggal dalam memanfaatkan perkembangan TIK dalam pembelajaran terutama dalam pengembangan bahan dan metode pembelajaran. Pemanfaatan ini dapat berupa pengembangan dan pemanfaatan TIK sebagai media dalam pembelajaran. Pemanfaatan TIK dalam pembelajaran diharapkan dapat membuat metode pembelajaran dan prosesnya menjadi lebih bervariasi sehingga menghasilkan perubahan perilaku yang optimal bagi mahasiswa. Saat ini di Universitas Raharja terdapat metode pembelajaran iLearning Plus yang mengandalkan kecanggihan teknologi sebagai media pembelajarannya. Kecanggihan teknologi dimanfaatkan sebagai media penunjang berjalannya iLearning Plus di Universitas Raharja. iLearning Plus telah menunjukan bahwa belajar dapat dilakukan dimana saja dan kapan saja. Media pembelajaran menjadi lebih efektif sehingga mahasiswa tidak mengalami hambatan dalam perkuliahan jarak jauh karena adanya sistem yang mendukung sistem pembelajaran iLearning Plus. Sistem tersebut adalah iDu(iLearning Education) iLearning Plus dimana merupakan media pembelajaran online yang menggunakan metode Learning Management System (LMS). Segala bentuk pembelajaran dapat dilakukan di iDu secara online melalui website iDu iLearning Plus bagi mahasiswa/i dan dosen agar kegiatan proses belajar mengajar dapat berjalan dengan efektif dan efisien dimanapun dan kapan pun yang diinginkan, tanpa tidak harus datang ke kampus dan bertatap muka langsung dengan sang dosen. iDu dirancang secara fleksibel sehingga mampu menghasilkan proses belajar mengajar yang berkualitas dengan didukung bimbingan dosen berpengalaman yang telah lulus iCP (iLearning Certified Professional) maupun iCM (iLearning Certified Master) dengan pembelajaran global. 
Pada sistem ini dosen dapat menyimpan bahan perkuliahan pada sistem iDu iLearning Plus dengan bentuk docs ataupun keynote yang dapat diunduh dan disimpan oleh mahasiswa pada pc ataupun ipad untuk pembelajaran dirumah jika sedang tidak memiliki akses internet. Selain itu, pada sistem ini juga terdapat assignment (tugas) yang diberikan oleh dosen yang diharapkan lebih mudah untuk dikerjakan dan juga dapat membuat mahasiswa lebih disiplin dalam pengumpulan tugas karena terdapat due date yang telah ditentukan oleh masing-masing dosen.

Kelebihan lain yang ada pada sistem ini adalah adanya pelaksanaan Ujian Online yang disebut dengan iOU (integrated Online Ujian). iOU (integrated Online Ujian) adalah sebuah aplikasi sebagai media pendukung dalam pembelajaran iLearning Plus dimana mahasiswa tidak lagi menjalankan ujian secara paper based, melainkan secara online. Dalam aplikasi ini terdapat kumpulan-kumpulan soal yang berada pada bank soal serta fasilitas gradebook secara langsung yang nantinya nilai - nilai hasil pembelajaran tiap harinya akan tertata rapi tanpa takut kehilangan data tersebut.

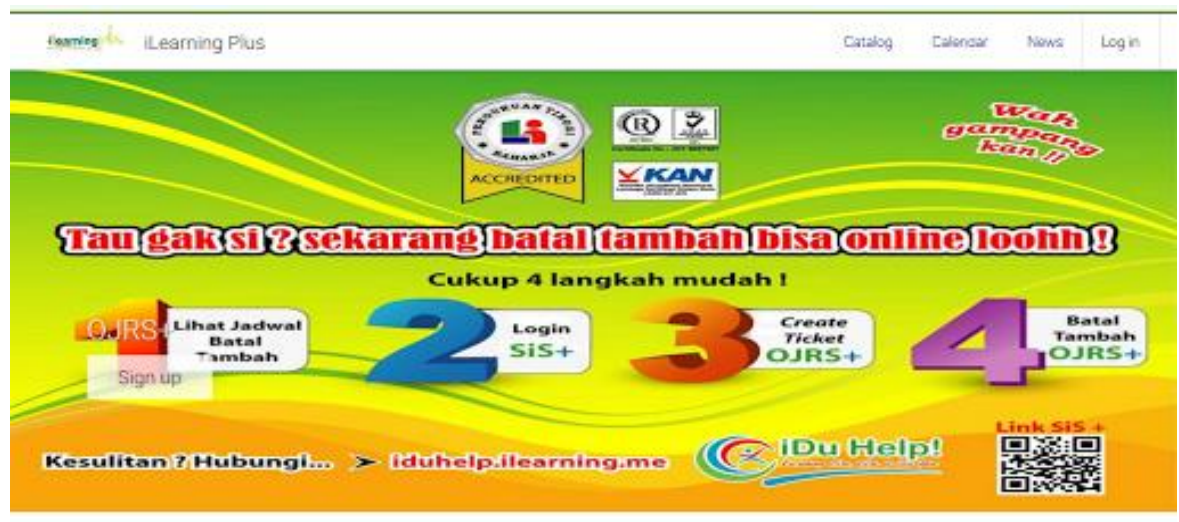

Gambar 3. Tampilan Awal iDu iLearning Plus

Gambar 3 merupakan tampilan utama pada iDu iLP. Untuk langkah yang pertama adalah login terlebih dahulu dengan user id dan password yang sesuai atau login melalui email Rinfo yang sudah terdaftar menjadi mahasiswa iLearning Plus.

Dalam mengerjakan assignment yang terdapat pada iDu iLP, mahasiswa diarahkan untuk menggunakan iMe sebagai media publikasi tugas yang sudah dikerjakan. iMe (iLearning Media) merupakan sebuah official portal blogging khusus untuk mahasiswa/i Raharja dan setiap mahasiswa/i Raharja akan mendapatkan subdomain sebagai media dokumentasi segala bentuk aktivitas pembelajaran. iMe (iLearning Media) mempunyai kelebihan yaitu pada domain yang digunakan yaitu domain milik sendiri yang menciri khaskan bahwa Perguruan Tinggi Raharja sudah menerapkan sistem iLearning. iMe (iLearning Media) sebagai salah satu pendukung kegiatan pembelajaran iLearning Plus di Perguruan Tinggi Raharja.

Dengan adanya media publikasi yang telah diberikan dapat digunakan untuk kegiatan pembelajaran dengan menggunakan iLearning Media(iMe) Class. iLearning Media(iMe) Class dapat digunakan dengan praktis, mudah serta lebih hemat biaya. Jika pada penulisan dokumentasi terjadi salah ketik atau kesalahan lain yang terdapat pada text tersebut maka bisa di edit kembali, tidak membuang-buang tinta ataupun kertas, mahasiswa pun menjadi lebih disiplin waktu dalam mengumpulkan tugas. Sehingga mahasiswa/i lebih semangat dan aktif melakukan sharing dalam berkomunikasi serta lebih berani dalam mengemukakan sesuatu hal baik tugas maupun pengalaman. Selain itu, tugas/pengalaman yang telah dibuat akan tersimpan dan tidak akan hilang di iLearning Media(iMe) Class.

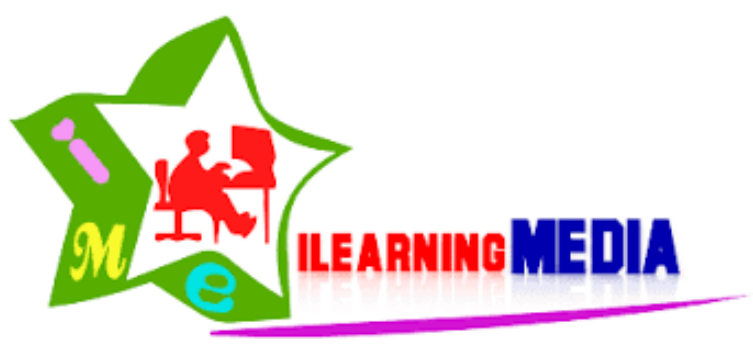

Gambar 4. Logo iLearning Media (iMe) 
iLearning Media(iMe) Class didalamnya memiliki fitur-fitur unik sebagai fitur pendukung, selain berisi text mahasiswa/i pun dapat memberikan link dan gambar serta dapat mengganti background sesuai selera yang diinginkan. Lalu terdapat pula kalender, Friend List, media social dan recent post. Fitur ini sangat membantu pada saat kegiatan belajar mengajar sehingga mahasiswa/i tidak mudah merasa jenuh jika mengunjungi site yang telah dimiliki. Dengan menggunakan iLearning Media(iMe) Class, dosen dapat mengetahui profil mahasiswa/i secara singkat dan dapat mengetahui secara rinci assignment yang telah dikerjakan oleh mahasiswa/i dengan cara melihat Sistem Kuliah Portofolio (SKUP) mahasiswa tersebut. Sistem Kuliah Portofolio (SKUP) merupakan tempat penyimpanan tugas yang lebih efektif dan mudah yang bertujuan agar proses penyimpanan tugas-tugas tidak tercecer atau hilang begitu saja saat pengumpulan tugas kepada dosen serta terdata rapih sehingga mahasiswa/i atau pun dosen lebih mudah untuk mencari tugas yang sudah dikerjakan. Kegunaan SKUP dalam iLearning Media(iMe) Class yaitu menghemat biaya dan juga sangat bermanfaat dalam metode perkuliahan jarak jauh yang diusung oleh iLearning Plus. Pada pengerjaannya, iLearning Media(iMe) Class menerapkan individualisme sehingga mendorong mahasiswa/i agar lebih berani mengungkapkan suatu hal dan lebih aktif dalam melakukan sharing komunikasi dengan teman atau dosen.

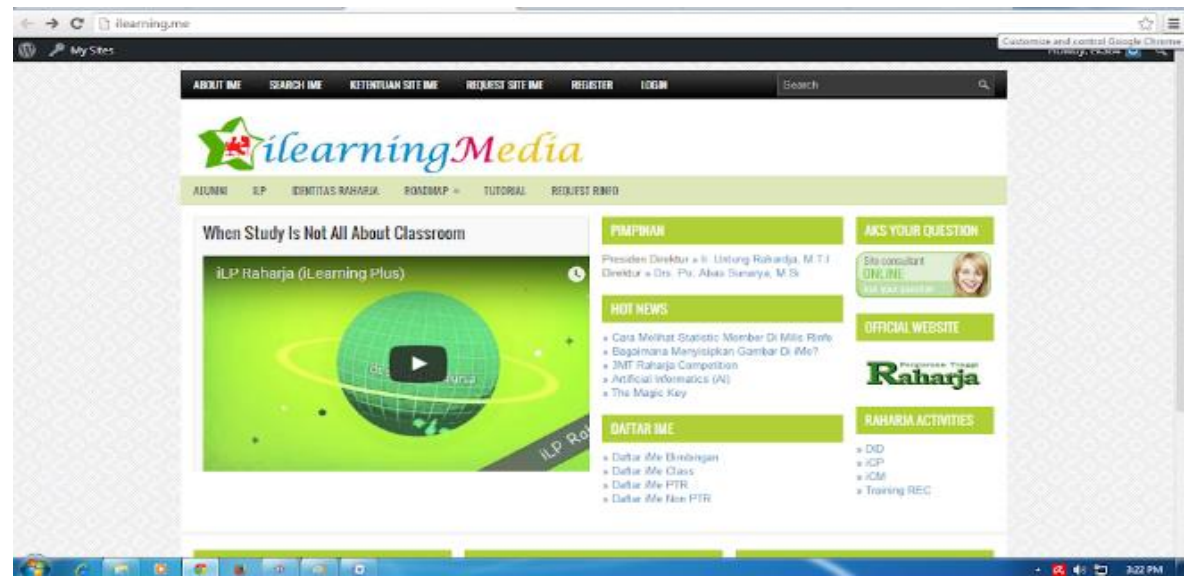

Gambar 5. Tampilan Utama iLearning Media (iMe)

Gambar 5 merupakan tampilan utama pada iLearning Media (iMe). Website tersebut dapat diakses dimanapun kapanpun oleh seluruh civitas akademika Universitas Raharja dengan menuju alamat website http://ilearning.me/. Untuk langkah yang pertama adalah login terlebih dahulu dengan menggunakan email Rinfo.

Dalam kegiatan pembelajaran iLearning Plus di Universitas Raharja banyak memakai email Rinfo sebagai media pendukung. Email Rinfo ini merupakan email resmi yang dipakai oleh seluruh civitas Universitas Raharja. Rinfo ini diadaptasi dari Gmail yang terdapat pada platform Google. Rinfo (Email Rahaja.Info) merupakan layanan komunikasi alat komunikasi yang paling utama dan paling vital untuk para Pribadi Raharja. Email ini disediakan oleh Universitas Raharja untuk semua Pribadi Raharja dengan kapasitas sampai $30 \mathrm{~GB}$ untuk masing-masing user. Rinfo memiliki domain tersendiri yaitu raharja.info sebagai domain bagi emailnya. Email Rinfo dapat diakses secara online melalui berbagai device seperti: komputer, laptop, handphone, tablet, dll. Tujuan diadakannya email Rinfo adalah komunikasi yang baik antar mahasiswa dimanapun dan kapanpun karena seluruh informasi mengenai kegiatan akademik akan diberikan melalui email Rinfo.

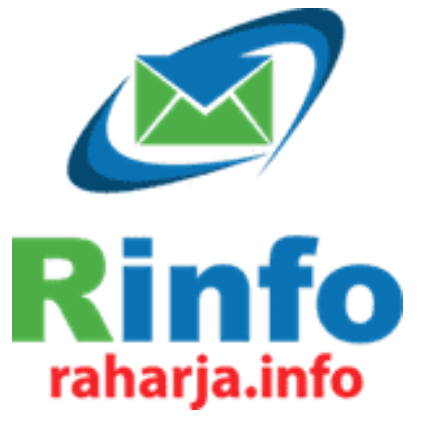

Gambar 6. Logo Rinfo 
Banyak fitur yang terdapat di dalam Rinfo yang bisa digunakan oleh civitas Universitas Raharja untuk menunjang kegiatannya terutama dalam proses pembelajaran. Fitur-fitur tersebut antara lain sebagai berikut :

1. Rinfo (raharja.info) yang berperan sebagai email. Email ini akan digunakan oleh user sebagai media pengiriman pesan antar civitas Universitas Raharja. Email ini akan memudahkan pengguna untuk mendapatkan informasi seputar akademik. Selain itu, Email ini juga akan mempermudah pekerjaan penggunanya karena pengguna tidak harus menuliskan alamat lengkap email yang dituju karena Rinfo akan memberikan beberapa saran alamat email dengan melihat huruf awal yang diketikan.

2. Rinfo Drive yang dapat digunakan sebagai media penyimpanan dan dapat membagikan (share) beberapa file. Selain itu, terdapat beberapa fitur tambahan seperti Rinfo Docs yang dapat membuat dokumen berformat teks, Rinfo Sheets untuk membuat spreadsheet, Rinfo Slides untuk membuat presentasi online, Rinfo Form untuk membuat dokumen formulir dan Rinfo Drawings yang dapat membuat, meng-edit dan membagikan gambar secara online.

3. Rinfo Sites yang dapat digunakan dalam membuat website dan halaman web yang diinginkan tanpa menggunakan bahasa coding. Fitur ini mudah digunakan dan tidak perlu men-download perangkat lunak lainnya.

4. Rinfo Calendar yang dapat digunakan sebagai pengingat (reminder) sekaligus sebagai pembuat pengumuman. Dimana nantinya pengumuman ini akan dikirimkan melalui email kepada para pengguna yang telah diundang.

5. Rinfo Hangouts digunakan sebagai media berdiskusi dengan cara chatting. Rinfo Hangouts juga dilengkapi dengan video chatting.

Selain fitur yang sudah disebutkan diatas, Rinfo juga digunakan sebagai media untuk berdiskusi dengan menggunakan Rinfo Groups. Dengan adanya milis di Rinfo Groups, mahasiswa dapat saling berbagi informasi seputar kegiatan perkuliahan, seperti berbagi link tugas pada iMe yang sudah dikerjakan, berdiskusi tentang pembelajaran, dan informasi lainnya menyangkut kegiatan perkuliahan.

Email Rinfo juga berfungsi sebagai penerima informasi yang disampaikan melalui sebuah notifikasi. Notifikasi yang disampaikan berkaitan erat dengan kegiatan pembelajaran yang berjalan, seperti penyampaian informasi mengenai tugas-tugas yang diberikan oleh dosen kepada mahasiswa, score atau nilai yang diperoleh mahasiswa, dan informasi mengenai kegiatan akademik yang berjalan pada Universitas Raharja dengan cepat tanpa mendatangi kampus. Hal tersebut sangat memberikan manfaat bagi mahasiswa iLearning Plus yang mengusung perkuliahan jarak jauh. Sistem notifikasi nantinya akan memberi informasi secara menyeluruh kepada mahasiswa, dan mahasiswa dapat langsung mengakses informasi tersebut. Sistem notifikasi di dalam iDu diintegrasikan melalui email Rinfo yang telah disediakan oleh Universitas Raharja, sehingga penyampaian informasi jauh lebih luas. Tidak hanya itu notifikasi pada sistem iDu ini dapat digunakan sebagai reminder bagi mahasiswa yang lupa mengerjakan tugas sampai batas waktu yang ditentukan

\section{SIMPULAN DAN SARAN}

Berdasarkan pembahasan di atas yang membahas tentang Peran Perkembangan Teknologi Informasi Dan Komunikasi Dalam Pembelajaran iLearning Plus Di Universitas Raharja, terbukti bahwa Perkembangan Teknologi Informasi Dan Komunikasi sangat memegang peran penting dalam proses pembelajaran iLearning Plus di Universitas Raharja. Pemanfaatan ini dapat berupa pengembangan sistem dalam pembelajaran. iLearning Plus telah menunjukan bahwa belajar dapat dilakukan dimana saja dan kapan saja. Dengan adanya iDu(iLearning Education) iLearning Plus sebagai media belajar online yang menggunakan metode Learning Management System (LMS) sebagai penunjang kegiatan pembelajaran iLearning Plus. Segala bentuk kegiatan pembelajaran dilakukan di iDu secara online melalui website iDu iLearning Plus bagi mahasiswa/i dan dosen agar kegiatan proses belajar mengajar dapat berjalan tanpa terikat tempat dan waktu.

Selain iDu(iLearning Education) iLearning Plus, terdapat iMe sebagai media publikasi tugas yang sudah dikerjakan. iMe (iLearning Media) merupakan sebuah official portal blogging khusus untuk mahasiswa/i Raharja untuk mendokumentasikan segala bentuk aktivitas pembelajaran. iLearning Media(iMe) Class dapat digunakan dengan praktis, mudah serta lebih hemat biaya. Selain itu, tugas/pengalaman yang telah dibuat akan tersimpan dan tidak akan hilang di iLearning Media(iMe) Class.

Dalam kegiatan pembelajaran iLearning Plus di Universitas Raharja juga mengandalkan Rinfo. Email Rinfo ini merupakan email resmi yang dipakai oleh seluruh civitas Universitas Raharja. Rinfo ini diadaptasi dari Gmail yang terdapat pada platform Google. Tujuan diadakannya email Rinfo adalah 
komunikasi yang baik antar mahasiswa dimanapun dan kapanpun karena seluruh informasi mengenai kegiatan akademik akan diberikan melalui email Rinfo. Rinfo juga digunakan sebagai media berdiskusi dengan menggunakan Rinfo Groups.

Pemanfaatan Perkembangan Teknologi Informasi Dan Komunikasi Dalam Pembelajaran iLearning Plus Di Universitas Raharja sudah cukup baik. Namun masih terdapat beberapa kekurangan pada sistem pembelajaran iLearning Plus saat ini. Adapun saran yang diberikan penulis sebagai bahan pertimbangan untuk mengembangkan bahkan meningkatkan sistem iLearning Plus ini agar lebih baik lagi. Sehingga kekurangan dan mungkin kesalahannya dapat diperbaiki. Berikut adalah beberapa saran dari penulis yaitu:Perlu adanya pengembangan sistem pembelajaran iLearning Plus yang lebih efektif dan efisien dengan menghadirkan fitur Live Discuss supaya mahasiswa dapat berkomunikasi secara langsung dengan dosen dalam jarak jauh. Perlu adanya penggabungan antara komponen-komponen media pendukung pembelajaran iLearning Plus supaya hanya terdapat 1 wadah yang akan menampung semua kegiatan mahasiswa tanpa perlu ke lain website

\section{UCAPAN TERIMAKASIH}

Peneliti mengucapkan terimakasih kepada para pihak yang sudah membantu dalam penyelesaian penelitian ini. Terutama kepada Tuhan Yang Maha Esa, karena berkat rahmat-Nya berupa kesehatan, kesempatan serta pengetahuan sehingga peneliti dapat menyelesaikan penelitian ini. Dan juga terimakasih kepada penulis 1 dan penulis 2 atas kerjasamanya sebagai pembimbing selama penelitian ini berlangsung. Terimakasih juga kepada Universitas Raharja yang sudah menyediakan fasilitas dalam penelitian ini, dan kepada pengelola iLearning Plus yang sudah bersedia membantu dan memberi arahan nya kepada peneliti.

\section{DAFTAR PUSTAKA (STYLE: JPTK - REFERENSI)}

[1] Diana, N., Walidain, S. N., \& Rahman, A. H. (2018). Integrasi Learning Management System (LMS) dan Simulasi PhET pada Pembelajaran Fisika Terhadap Keterampilan Proses Sains. QUARK: Jurnal Inovasi Pembelajaran Fisika Dan Teknologi, 1(1), 36-40.

[2] Riansyah, Z., Lumbantoruan, J., \& Hadi, H. (2018). STUDI DESKRIPTIF KEGIATAN PENGEMBANGAN DIRI BERNYANYI PADA ANAK TUNANETRA DI SEKOLAH LUAR BIASA WACANA ASIH KOTA PADANG. Jurnal Sendratasik, 7(1), 55-60.

[3] Rahardja, U., Aini, Q., \& Zuliana, S. R. (2016). METODE LEARNING MANAGEMENT SYSTEM (LMS) IDU UNTUK MENDUKUNG KEGIATAN BELAJAR MENGAJAR MIT PADA PERGURUAN TINGGI RAHARJA. CICES, 2(2), 156-172.

[4] Ariessanti, H. D., \& Aini, Q. (2017). Penerapan iDu iLearning Plus berbasis Gamification Sebagai Media Pembelajaran Jarak Jauh pada Perguruan Tinggi. Technomedia Journal, 1(2), 37-49.

[5] Yusup, M., Aini, Q., \& Pertiwi, K. D. (2016). Media Audio Visual Menggunakan Videoscribe Sebagai Penyajian Informasi Pembelajaran Pada Kelas Sistem Operasi. Technomedia Journal, 1(1), 126-138.

[6] Aini, Q., Irwin, R. H., \& Marjayanti, E. (2017). Notifikasi Pembelajaran iLearning Melalui Media Aplikasi iDu dengan Menggunakan E-mail Rinfo. Technomedia Journal, 1(2), 1-11.

[7] Rahardja, U., Aini, Q., Apriani, D., \& Khoirunisa, A. (2019). Optimalisasi Informasi Manajemen Laporan Assignment Pada Website Berbasis Content Management System. Technomedia Journal, 3(2), 213-223.

[8] Hayat, A., Maesaroh, S., \& Ardiana, M. (2019). Perancangan Aplikasi Green Media Berbasis Smartphone Sebagai Sarana Media Education dan Entertainment Pada Perguruan Tinggi. Technomedia Journal, 3(2), 157-170.

[9] Rahardja, U., Tejosuwito, N. J., \& Armansyah, F. S. (2017). Perancangan Aplikasi Pen+ Berbasis Mobile untuk Memudahkan Kinerja Dosen pada Perguruan Tinggi. Technomedia Journal, 1(2), 50-60.

[10] Bibi, S. (2016). Efektivitas Penerapan Blended Learning Terhadap Tingkat Pemahaman Mahasiswa Mata Kuliah Algoritma Dan Pemrograman. Jurnal Pendidikan Informatika dan Sains, 4(2), 274-286.

[11] Fitri, E., Ifdil, I., \& Neviyarni, S. (2016). Efektivitas layanan informasi dengan menggunakan metode blended learning untuk meningkatkan motivasi belajar. Jurnal Psikologi Pendidikan dan Konseling: Jurnal Kajian Psikologi Pendidikan dan Bimbingan Konseling, 2(2), 84-92.

[12] Mwalumbwe, I., \& Mtebe, J. S. (2017). Using learning analytics to predict students' 
performance in moodle learning management system: a case of mbeya university of science and technology. The Electronic Journal of Information Systems in Developing Countries, 79(1), 1-13.

[13] Islamiyah, M., \& Widayanti, L. (2016). Efektifitas Pemanfaatan E-Learning Berbasis Website Terhadap Hasil Belajar Mahasiswa STMIK Asia Malang Pada Mata Kuliah Fisika Dasar. Jurnal Ilmiah Teknologi Informasi Asia, 10(1), 41-46.

[14] Yunis, R., \& Telaumbanua, K. (2017). Pengembangan E-Learning Berbasiskan LMS untuk Sekolah, Studi Kasus SMA/SMK di Sumatera Utara. Jurnal Nasional Teknik Elektro dan Teknologi Informasi (JNTETI), 6(1).

[15] Kusumantara, K. S., Santyadiputra, G. S., \& Sugihartini, N. (2017). Pengaruh E-Learning Schoology Terhadap Hasil Belajar Simulasi Digital Dengan Model Pembelajaran Savi. Jurnal Pendidikan Teknologi dan Kejuruan, 14(2).. 